\title{
Nos Caminhos da História com Dante de Laytano
}

Moacyr Flores

Dante de Laytano, como todos os intelectuais de sua geração, começou escrevendo crítica cinematográfica em jornal, depois pequenas crônicas, até se tornar professor e historiador de renome. Bacharel em Direito, logo após foi nomeado promotor público em Rio Pardo e a seguir juiz em Torres. Optando pelo magistério, lecionou na Pontifícia Universidade Católica do RS (PUCRS) e na Universidade Federal do RS (UFRGS), onde introduziu em ambas a disciplina História do Rio Grande do Sul, causando espanto em algumas pessoas que achavam que não haveria assuntos para ministrar aos alunos. Sua bibliografia é vasta, abrangendo vários temas da história regional, crônicas sobre o cotidiano, crítica literária e contos. Realizei várias entrevistas com o antigo mestre, elaborando uma síntese do que foi comentado, mas mantendo nas respostas o estilo e a verve de Dante de Laytano.

M. F. - Por que um estudante de Direito e crítico de cinema se interessou pela História do Rio Grande do Sul?

Laytano - Na minha geração não se começava com estudos históricos, não se pesquisava. Começava-se pela literatura, poesia e contos. Os jornais diários sempre abriam colunas aos literatos. Uma figura que faço questão de lembrar é a do doutor Eduardo Duarte, que dirigiu e fundou o Arquivo Histórico do RS. Ele realizou uma carreira de funcionário no Arquivo Público, mas como era um apaixonado pelo passado e pela fonte histórica, organizou de maneira modelar o material histórico, estabelecendo uma seção especial que ele mais tarde conseguiu levar para o Museu Júlio de Castilhos, iniciando assim a segunda fase da 
documentação histórica do Rio Grande do Sul, fase de coleta, de classificação, de guarda, de cuidado e de pesquisa. Quando lhe fazia uma visita no Museu Júlio de Castilhos, o doutor Eduardo Duarte mostrou-me documentos interessantes, para que eu desse uma lida e escrevesse alguma coisa. Foi o estopim para que nascesse o pesquisador. A terceira fase da documentação foi a criação do Arquivo Histórico do Rio Grande do Sul, da qual também participei redigindo um anteprojeto que me foi solicitado. Convidei para sua elaboração dois ou três amigos, entre eles o professor Astrogildo Fernandes, que muito me ajudou.

$M . F$. Depois que se interessou pela pesquisa, quando começou a escrever História?

Laytano - Bem, acho que comecei a me interessar pelo campo da pesquisa histórica pela razão de fatos imediatos, por exemplo, eu fui ser promotor público na cidade de Rio Pardo, que é uma cidade histórica, uma cidade tradicional, uma cidade antiga e que tem um arquivo magnífico. Até então trabalhava em jornal, com crônicas literárias, críticas de cinema, escrevia sobre biografias, livros, esta espécie de coisa. Então a impressão que Rio Pardo me deu é que merecia uma pesquisa em torno do passado histórico, embora existissem três ou cinco trabalhos pequenos a respeito de Rio Pardo, mas percebi que faltava um livro abrangente, desde o nascimento de Rio Pardo, de seu crescimento sistemático, do tratado de Madrid, da fronteira no século XVIII, onde terminava o Brasil. Grande tema. Desta forma eu ingressei no caminho da História pela sedução da paisagem, onde estava trabalhando. Diante de meus olhos Rio Pardo era realmente uma grandeza do passado, que desempenhou papel importantíssimo em nossa história. Então foi o contágio, a inspiração da terra e do lugar.

M. F. - Este descobrimento da História foi espontâneo ou alguém lhe pediu que escrevesse um livro sobre Rio Pardo?

Laytano - Não, ninguém me pediu que escrevesse, foi espontâneo. Andando pela paisagem do Rio Pardo: aqui foi o forte, não tinha mais nada, como não tem até hoje. Forte de Jesus, Maria e José; tratado de Madrid, 1750, fronteira sul do Brasil, com sua posição dominando a entrada do rio Pardo no rio Jacuí. Primeiro, o caminho fluvial de como se podia navegar nele, de Porto Alegre ao interior. Depois o lugar do forte, que dominava a navegação fluvial. Baseado nisso passei a interpretar, examinar porque Portugal se interessou a montar ali um dispositivo político-militar, que foi o regimento dos Dragóes do Rio Pardo. 
Quase um século de vida, juntamente por isso para não só garantir a fronteira de Rio Pardo e depois jogá-la até o rio Uruguai, como também que Rio Pardo podia desempenhar um papel administrativo, como desempenhou, pois Rio Pardo foi um dos primeiros quatro municípios criados no Rio Grande do Sul, em 1809.

M.F. - Como começou a pesquisa? Buscou a orientação de alguma pessoa ou tomou algum livro como base? Como chegou documentação?

Laytano-Quando achei que podia estudar Rio Pardo e pelas razões que minhas funções de promotor me davam acesso aos documentos, arquivos, prefeituras, dossiês de famílias antigas e pessoas importantes. Numa cidade do interior tinha poucas opções para ocupar as horas livres. São cidades acolhedoras, muito simpáticas, agradáveis, mas a escolha é limitada: jogo de cartas, dados e coisas deste tipo. Acho bonitó o jogo de roleta e corridas de cavalo, mas não tenho vocação para jogador. Então restou o estudo. Independente disso, vim a Porto Alegre ao Arquivo Histórico, que era seção do Museu Júlio de Castilhos, dirigido pelo Dr. Eduardo Duarte. Fiz perguntas a ele sobre documentos, de como poderia estudá-los. Terminei sendo um discípulo de quem me orientou sobre os documentos e materiais que eu deveria pesquisar. Achei que era bom conversar com uma autoridade sobre o assunto, pois não era minha seara e eu tinha que começar estudos, pesquisas, avaliações e daí nasceu o gosto pela História e um livro sobre Rio Pardo.

O Dr. Paulo Duarte me desvendou numerosas teses, me orientou naquele cipoal de documentos, naquela floresta de papel, onde pude ver coisas notáveis como autógrafos de Bento Gonçalves, até um relatório de Gomes Jardim. A gente podia ler toda a história da Revolução Farroupilha envolvendo-se nas consultas dos papéis do Arquivo Histórico do Rio Grande do Sul. Ali está toda a história do Rio Grande, escrita documental, isto então me marcou.

Comecei a me dedicar aos trabalhos históricos em todos os lugares em que fui trabalhar como promotor público, sempre fiz um estudo sobre o lugar. Por exemplo: Torres, vocabulários dos pescadores, os limites do município, a geografia local, a formação do presídio militar como local de cobrança de impostos. Cachoeira: história do rio Jacuí e a abrangência do forte militar de Rio Pardo. Em todos os lugares que vivi, dediquei-me à pesquisa da história local, municipal ou regional. Em Rio Pardo organizei o arquivo da Prefeitura, onde o doutor Eduardo Duarte já tinha feito um catálogo. Limitei-me a organizar um fichário e pude elaborar 
alguns artigos com esta documentação sobre monumentos, vida política, economia, religião e igrejas. Eu parto do seguinte princípio que não há história geral que não venha de uma história local; não há história universal que não comece por uma história nacional, estadual, municipal ou regional. A soma desta é a história geral. Passei assim a fazer História, o meu assunto e jamais me libertei dele e com grande prazer continuo a ter o gosto pela pesquisa.

M. F. - Quais os autores que influenciaram em sua formação de historiador?

Laytano - Dois autores me deixaram influências enormes. O primeiro, Afonso Guerreiro Lima, A. G. Lima, que foi meu livro de História do Rio Grande do Sul: Cronologia de História do RS, Geografia do RS, Manuscrito Brasileiro. Era um professor dos raros em sua geração que se interessava pela história local. Na nossa é a mesma coisa, e na tua também, Moacyr, somos poucos que se dedicam à história local, história da terra natal. Ficam na história geral, na história antiga, mas a história da terra onde a gente vive não é fácil encontrar. Guerreiro Lima fazia a história local e isto me impressionou muito. Outro historiador que me marcou foi Aurélio Porto, por uma razão muito simples, ele só escrevia à luz de documentos: Revolução Farroupilha, colonização alemã, tudo com documentos de arquivos, relatórios, correspondência. Achei interessantíssimo de como através de uma carta podia-se fazer uma história. Quem escreveu a carta, para quem, o que foi escrito... Tudo isto Aurélio Porto me mostrou e que também a correspondência é assunto da história, como também é assunto a biografia, a vida da cidade, a vida econômica e a vida moral. Foram duas grandes iniciações: Guerreiro Lima e Aurélio Porto. Eles me deram a direção: o historiador deve fazer duas lições. A primeira com Aurélio Porto, aprendi que não se pode escrever a história sem documentos. Escreve, prova. O aval é o documento. A história tem que ser provada e comprovada. É a lição número um. Com Guerreiro Lima aprendi que o espírito de síntese deve dominar o historiador, como projeção do fato, não é bem o resumo, mas a síntese filosófica da matéria que se vai encarar.

M.F. - Quando o senhor estava iniciando na história, predominava a doutrina de Augusto Comte. Que influências o positivismo exerceu em seu pensamento? Até que ponto foi esta influência?

Laytano-Absoluta! Primeiro que eu estava num colégio positivista, era o Júlio de Castilhos e lá os professores no inculcavam coisas de 
Augusto Comte, davam frases a nós meninos. Falavam muito da doutrina, embora não tivéssemos capacidade de compreender por falta de formação filosófica e nem idade, a perspectiva de Comte. Mas terminando o ginásio comecei a ver as bases, as raízes que a filosofia tinha me dado. Eu dizia: mas isto aqui é Augusto Comte, é positivismo, é origem do republicanismo do Rio Grande do Sul, é Júlio de Castilhos, líder que morreu jovem e implantou a idéia positivista no sistema político riograndense e durou depois, como herança e por transmissão do poder até o Dr. Borges de Medeiros. Que uma vez disse que não era positivista, mas que seguia o sistema de Júlio de Castilhos, que era positivista.

M.F.-Mas depois o senhor começou a pesquisar folclore e o negro. Onde buscou os parâmetros para esta nova caminhada na história?

Laytano - Aí eu percebi que há uma história escrita, documental e outra história, a oral. Então fui ver o folclore. A história do povo é oral, é aquela que o povo fabrica que o povo se manifesta. Por exemplo, as festas do Divino Espírito Santo, Corpus Christi e todas as atividades, não só as religiosas, mas também as de ciclo econômico, todas as que o povo participa: as corridas de cavalo, a marcação do gado. Fui percebendo que todas estas coisas obedeciam a um ciclo, que se encaixavam dentro de normas. Ciclo econômico, ciclo pastoril, ciclo agrícola e que isto precisava ser interpretado. A história do Rio Grande do Sul era uma que tinha que ser vista através do poder local, quer dizer a riqueza local que era a pastoril, que durante um século foi o desenvolvimento do Rio Grande do Sul.

M. F. - O senhor manteve correspondência com Gilberto Freyre e Câmara Cascudo, até que ponto eles afetaram em suas linhas de pesquisas de folclore e de história social?

Laytano - Tudo. Gilberto Freyre foi minha grande influência, eu vi que as coisas que determinam os fatos históricos não são apenas as solenes, as políticas, as administrativas ou os grandes fatores.

M. F. - Aí o senhor já estava escapando das linhas teóricas do positivismo que transforma o herói no impulsor da História.

Laytano - Já estava. Os pequenos fatos, os costumes a maneira de vestir, a maneira de conviver na época, os hábitos e os jogos também representam a história. Há duas histórias, a particular e a geral, a documental e a oral. Parti para a coleta da história oral e me dei muito bem! Até hoje está tudo para se fazer, pesquisei uma parte ínfima da 
História do Rio Grande do Sul, que é magnífica. Não só cancioneiro, é claro, está registrado, mas a história política que tem um conteúdo de história oral, que muita coisa não se publica, porque os personagens ainda estão vivos. Todos os líderes, como Vargas, João Neves da Fontoura, Borges de Medeiros, tiveram seus pontos fracos, seus pontos diferentes. Eu não sou da história de anedotas, não gosto, acho inconveniente. Mas agrada sempre aquele que não gosta da história, dizem que uma maneira de atrair a pessoa que não gosta dos estudos históricos, é contar anedota. Não acho que isto seja certo, nem razoável. Não vale a pena pensar numa coisa desse tipo. Acho eu.

M. F. - De que maneira conciliou o jornalismo com o magistério e este com a pesquisa?

Laytano - Passando da crítica literária, da crônica e do conto para a História, houve uma transformação muito grande na formação do pensamento. Levei para a História alguns métodos, como por exemplo: o jornalismo. O jornal deu ao historiador o espírito de síntese e o sentido de clareza, pois no jornal não se pode ser longo e nem atabalhoado de material. Este espírito venho trazendo do jornalismo, quando fazia crônica, contos e reportagens. Num segundo aspecto quando fui chamado para ser professor, pude levar para a pesquisa uma metodologia que o pesquisador que não exerce o magistério tem algumas fronteiras ou limitações, no sentido de divulgação do fato histórico. Como professor sempre levei minhas pesquisas para a sala de aula, testando minhas idéias.

M. F. - Entre os temas da História regional, quais os que mais se dedicou em suas pesquisas.

Laytano-Meu primeiro assunto é a Revolução Farroupilha. Como bom gaúcho tinha que pagar o meu tributo: começar a História com a Revolução dos Farrapos. Escrevi um livro, publicado pela editora Globo, que foi muito bem recebido, apesar de eu ser um menino de vinte e poucos anos. A História da República Rio-Grandense foi editada novamente pela Sulina.

Nas pesquisas sobre a Revolução Farroupilha achei muito material, como por exemplo, o caderno do poeta Sebastião Mena, grande voz dos revolucionários, com poemas ainda inéditos.

Fiz a História da República Rio-Grandense baseada toda no jornal $O$ Povo e em documentos da época. Não copiei de ninguém, a não ser os princípios doutrinários, que a Revolução Farroupilha foi uma revolução 
brasileira e não uma revolução platina; que a revolução Farroupilha foi uma idéia republicana que surgiu no decorrer de dez anos, a partir do grupo de Evaristo da Veiga, que não podendo fazer a república brasileira, pretendia fazer pelas províncias, até chegar à federação brasileira. Estas idéias foram elaboradas por Aurélio Porto, Eduardo Duarte e Souza Docca.

Depois da Revolução Farroupilha passei a estudar o negro. Não há na História do Rio Grande do Sul uma contribuição igual à da Bahia, ou igual a de Minas Gerais, porque o número de negros é de $10 \%$ a $15 \%$ da população rio-grandense. Estudei o comportamento do negro no seu legado religioso, no espírito guerreiro, no vocabulário gauchesco. Estudei também algumas sobrevivências de costumes africanos, como por exemplo a festa de Nossa Senhora dos Navegantes. Escrevi uns 10 ou 15 artigos, seguindo a filosofia de Gilberto Freyre de que o negro sempre foi um grande injustiçado e que não era o elemento marginal como os historiadores comprometidos gostam de dizer, mas que o negro teve um papel muito importante na História do Rio Grande do Sul. Estive em Angola, Moçambique e Congo, complementando estas pesquisas.

Outra temática foi a dos açorianos. Partindo do estudo da fundação de Porto Alegre e de outras cidades, fiquei impressionado com a sobrevivência do vocabulário açoriano como brete, peão no linguajar gauchesco. Escrevi uma monografia sobre as nove ilhas do Arquipélago dos Açores. Busquei as fontes primárias deste legado à formação do Rio Grande do Sul, atenuando a influência platina, pois os açoritas foram $55 \%$ da população riograndense no século XVIII.

Outro assunto que sempre me apaixonou foi o folclore, como um substrato vivo, como uma decorrência da formação histórica. Dentro da filosofia das tradições populares, que é o saber do povo, o folclore do Rio Grande do Sul me levou à tese de que ele não é platino, mas luso-açoriano-brasileiro. Escrevi numerosas monografias e tratados sobre esta temática, inclusive estudo sobre o cavalo e o folclore gauchesco. Segundo Oliveira Viana o Rio Grande do Sul era uma civilização eqüestre, sendo o gaúcho a pé um marginal. Por aí pode-se ver a importância do folclore campeiro, da estância, do gado e do urbano na formação do Rio Grande do Sul.

Estudei também a formação das cidades do Rio Grande do Sul. Mantive uma coluna no jornal Correio do Povo, sobre o nascimento de cidades. Parece-me que há uma confusão sobre o assunto, pois os sociólogos julgam que este tema é privilégio deles, nada tenho contra os 
sociólogos, acho-os formidáveis, mas a sociologia saiu da história, e foi Augusto Comte que a inventou em 1835, é uma ciência nova, enquanto que a História é tão velha quanto o mundo.

Os assuntos do Rio Grande do Sul são muito amplos e seus horizontes se perdem.

M.F. -Em sua vivência, em sua experiência, como viu o Dr. Borges de Medeiros como administrador, como político e como personagem histórico?

Laytano - O Dr. Borges foi um administrador de contexto moral. Tudo era em função da decência, tudo era em função de o Estado ter o orçamento bem aplicado. Até havia uma tradição popular: dizia-se que todos os dias o Diretor do Tesouro ia ao palácio para expor o movimento do caixa. Não gastava demais e nem se botava dinheiro fora. Essa foi uma tradição. O Dr. Borges realmente foi uma reserva moral, era atacado políticamente por seus adversários, principalmente pelos vários períodos de governo que ele exerceu. Entre seus adversários havia Assis Brasil, um grande homem, um notável estadista, uma figura marcante na história do Rio Grande do Sul. Mas o Dr. Borges ainda conseguiu ser o dominador daquele ciclo. Não era fácil desalojá-lo do poder. No ciclo de Borges de Medeiros havia homens de uma envergadura extraordinária. Eram figuras marcantes, figuras escolhidas como representes das diversas categorias.

M.F.-Para encerrar a entrevista, algumas perguntas para respostas rápidas. Nome de um historiador estrangeiro?

Laytano. - Arnold Toynbee.

M. F. - E de um nacional?

Laytano - Capistrano de Abreu e regional, Aurélio Porto.

M. F. - Que livro de História mais lhe interessou?

Laytano - História da Independência do Brasil, de Vanhargen.

M. F. - Algo que lhe aconteceu nas pesquisas?

Laytano - Tudo o que se procura não se acha, só se acha aquilo que não se procura. Assim encontrei coisas realmente notáveis.

M.F.-Quando o senhor estuda as causas da Revolução Farroupilha está bem clara a doutrina positivista?

Laytano - Fatores dinâmicos e fatores estáticos. De acordo com Comte as idéias eclodem de duas formas: a idéia que a pessoa pode 
executar e aquela que a pessoa pode ser inspirada. Achei uma formulação interessante para explicar a Revolução Farroupilha no Rio Grande do Sul. Os fatores estáticos: o Rio Grande do Sul como região de fronteira, a vizinhança e as manifestações do Prata. Os fatores dinâmicos eram o espírito político da formação do gaúcho brasileiro, que sempre andava a cavalo por ser um militar ou um fazendeiro. Sempre associado à idéia de comando, de ação, de atividade à sua própria personalidade.

M. F. - Uma desilusão na pesquisa?

Laytano - Quando se estuda sobre um personagem e ele é justamente o contrário que a gente pensa que ele é, que até é um sujeito sem-vergonha, horroroso e incrível. Não posso citar nenhum, embora tenha os nomes na ponta da língua.

M. F. - Qual o personagem da História do Brasil que poderia citar por admiração?

Laytano - D. Pedro I, que enganou os republicanos separatistas, proclamando a independência e depois abdicou, entregando o governo aos golpistas liberais, que ficaram sem condições de governar. Era inteligente, culto, compositor.

M. F. - E da nossa História regional?

Laytano - Júlio de Castilhos, que representou a mocidade idealista que veio da Faculdade de Direito de S. Paulo. Figura de líder notável, com formação filosófica e que redigiu a Constituição Rio-Grandense, uma obra prima do Direito Público brasileiro.

M. F. - O que poderíamos fazer para maior valorização da história?

Laytano - Temos que levar a História para a Universidade e trazer de lá nossos alunos, para que nos sigam, fazendo nossos herdeiros. A História não é ausência do atempo, mas o passado, mais o presente igual ao futuro, segundo Wells. Fazendo com que as idéias continuem com aqueles que nos ouvem em nossas aulas e com aqueles nos lêem. 